\title{
DERMOID CYSTS OF THE TONGUE: A REPORT OF FIVE CASES AND \\ REVIEW OF THE LITERATURE
}

Paul C. Edwards ${ }^{1}$ M.Sc., D.D.S., Liz Lustrin ${ }^{2}$ M.D., and Elsa Valderrama ${ }^{3}$ M.D.

${ }^{1}$ Oral and Maxillofacial Pathology, Department of Dental Medicine, Long Island Jewish Medical Center, New Hyde Park, NY.

${ }^{2}$ Attending, Division of Neuroradiology, Department of Radiology, Long Island Jewish Medical Center, New Hyde Park, NY.

${ }^{3}$ Chief, Division of Pediatric Pathology, Department of Pathology, Long Island Jewish Medical Center, New Hyde Park, NY.

Author's accepted manuscript; final version published as:

Edwards PC, Lustrin L, Valderrama E. Dermoid cysts of the tongue: report of five cases and review of the literature. Pediatr Dev Pathol. 2003 Nov-Dec;6(6):531-5. 


\begin{abstract}
Dermoid cysts of the tongue are uncommon. To date, there have been nine reported cases in the English language literature. In this article, we describe five cases accessioned at our institution over a 12-year period, two of which have previously been reported ${ }^{15}$. The prevalence of dermoid cysts at our institution over this period was quite low. Of 500,281 surgical cases, $0.15 \%$ ( 765 cases $)$ were dermoid cysts. Of these, five were from the tongue; representing only $0.7 \%$ of the dermoid cysts accessioned and less than $0.001 \%$ of the total surgical specimens. The literature is reviewed and the possible origin of these lesions is discussed.
\end{abstract}

Key words: dermoid cyst, lingual, MRI, pathogenesis, tongue Author's accepted manuscript; final version published as:

Edwards PC, Lustrin L, Valderrama E. Dermoid cysts of the tongue: report of five cases and review of the literature. Pediatr Dev Pathol. 2003 NovDec;6(6):531-5. 


\section{INTRODUCTION}

The most common lesions of the tongue in a child include hemangioma, lymphangioma, neurofibroma, pyogenic granuloma, mucocele, osseous choristoma, salivary gland neoplasm, lingual thyroid, irritation fibroma, and granular cell tumor. Although rare, the dermoid cyst should also be included in the differential diagnosis.

The term "dermoid cyst" is often used generically to describe three histlogic entities: the epidermoid cyst, the "true" dermoid and the teratoid cyst. An epidermoid cyst is a keratin-filled developmental cyst lined by stratified squamous epithelium with a fibrous wall but lacking adnexal structures. In the oral cavity, epidermoid cysts are believed to represent the minimal manifestation, a forme fruste, of an epidermoid-dermoid-teratoid cyst spectrum ${ }^{1}$. The dermoid cyst is differentiated from the epidermoid cyst by the presence of adnexal structures such as sebaceous elements, sweat glands and hair follicles within the cyst lining. The teratoid cyst is a cystic form of teratoma that contains derivatives of ectoderm (e.g. skin appendages), mesoderm (e.g. muscle, blood vessels, bone) and endoderm (e.g. gastrointestinal lining) within the cyst wall. Teratoid cysts are extremely rare.

Dermoid cysts are commonly found in relation to midline structures, with head and neck lesions accounting for approximately $7 \%$ of all dermoid cysts. Most oral dermoid cysts are located in the floor of the mouth. Dermoid cysts of the tongue are rare. To date, there have been nine reported cases in the English language literature that histologically were 
true dermoid cysts (Table 1). A case of an intralingual dermoid cyst has even been described in a dog ${ }^{2}$. 


\section{CASE REPORTS}

All dermoid cysts accessioned at the Department of Pathology at the Long Island Jewish Medical Center, New Hyde Park, New York, over a 12-year period (01/01/1989 to $02 / 28 / 2002$ ) were identified. Of 500,281 total surgical specimens obtained during this period, 765 dermoid cysts were identified $(0.15 \%)$. Of these, five were located within the tongue (Table 2); representing only $0.7 \%$ of the dermoid cysts accessioned and less than $0.001 \%$ of the total surgical specimens.

Case 1: A 10-year old girl underwent surgical excision of a lesion of the right sublingual triangle and tongue. Histological examination revealed stratified squamous orthokeratinized epithelium lining a keratin-filled cystic lumen (Fig.1). Sebaceous glands and hair follicles were identified within the cyst wall.

Case 2: A 17-year old female patient presented with a lesion of the ventral tongue extending to the floor of the mouth (Fig.2). Fine needle aspiration biopsy of the lesion revealed acellular proteinaceous material, consistent with the contents of a cyst. The mass, measuring $6.5 \times 4.2 \times 1.2 \mathrm{~cm}$, was surgically excised. Grossly, a nodular area measuring $1.0 \mathrm{~cm}$ was identified on the surface of the specimen. Microscopic examination revealed a cyst wall composed of fibrocollagenous tissue containing bundles of smooth muscle. The cyst was lined by keratinized epithelium with skin and adnexal structures. Sections from the grossly nodular area showed necrosis and chronic inflammation within the cyst wall. 
Case 3: A 5-month old boy presented with a one-week history of irritability and fever. Physical exam revealed an enlarged tongue with induration of the ventral surface. MRI demonstrated a large irregular hyperintense tongue mass surrounded by a hypointense rim on T2-weighted imaging (Fig. 3). The floor of the mouth was not involved. The lesion was surgically removed. The submitted specimen consisted of two pieces of tan fibrotic cystic wall tissue measuring $2.2 \times 0.6 \times 0.4 \mathrm{~cm}$. The cyst wall was lined by skin adnexal structures and contained chronic inflammatory cells and foamy macrophages, suggestive of a rupture of the cyst wall.

The patient returned three and a half years later with a large cystic mass of the midline of the neck., which on excision proved also to be a dermoid cyst.

Case 4: A 14-year old male with a history of allergic rhinoconjunctivitis and attention deficit and hyperactivity disorder presented with an intraoral mass of the right side of the tongue with associated submental swelling of 3 weeks duration which was unresponsive to antibiotic therapy. Bilateral cervical lymphadenopathy was also noted Surgical excision of the mass was performed transorally. The gross specimen consisted of a well-circumscribed lobular cystic mass measuring $4.0 \times 3.5 \times 1.5 \mathrm{~cm}$ (Fig. 4). The cyst wall was composed of a stratified squamous epithelium with orthokeratin production (Fig. 5). Sebaceous glands were present in the cyst wall. 
Case 5: A 12-year old male with a history of mild asthma presented with a large lingual mass of one-month duration causing elevation of the floor of the mouth, restriction of tongue movement and speech impairment.

A midline mucosal incision was made at the root of the ventral tongue, revealing a $3.2 \mathrm{x}$ $2.7 \times 1.5 \mathrm{~cm}$ intralingual white mass, Microscopic examination of specimen revealed a cystic mass lined with stratified orthokeratinizing squamous epithelium. Sebaceous elements were noted within the cyst wall. 


\section{DISCUSSION}

The pathogenesis of lingual dermoid cysts is unknown. The congenital nature of these lesions would seem to suggest that they arise from aberrant embryonic development.

Embryologically, the tongue consists of two separate parts ${ }^{3}$. The mucous membrane of the anterior two-thirds of the tongue develops from the first branchial arch. Specifically, three swellings of primitive mesenchyme, the midline tuberculum impar and bilateral lingual swellings, merge to form a single mass from which the anterior two-thirds of the tongue is formed. The mucosa of the posterior third of the tongue is formed from a large midline swelling of mesoderm of the second, third, and fourth branchial arches; the hypobranchial eminence. The musculature of the tongue arises from the anterior migration of occipital somites.

A number of different theories have been proposed to explain the pathogenesis of the dermoid cyst.

The most popular theory is that they arise from residual epithelial rests sequestered during the medial migration of the lateral lingual swellings during the development of the anterior segment of the tongue. ${ }^{4}$ The presence of totipotent blastomers within these enclaves would account for the presence of any or all three of the basic germ layers (ectoderm, endoderm and mesoderm) within the cyst lining and therefore the observed spectrum of epidermoid-dermoid-teratoid cysts. 
It has also been proposed that traumatic implantation of epithelium may account for the development of these cysts. However, their congenital nature and the absence of any history of trauma in most cases would argue against this theory ${ }^{14 .}$

A third theory is that dermoid cysts may develop from normal epithelial bands which are destined to form other epithelial-derived structures of the tongue, such as the serous glands of von Ebner ${ }^{14}$. According to this theory, these embryonic epithelial bands become displaced from their expected destination and in the absence of proper inductive influence from the ectomesenchyme, transform into less specialized structures such as sebaceous glands and hair follicles.

Clinically, the lingual dermoid cyst most commonly presents as a doughy fluctuant swelling of the midline of the tongue, although a number of the cases previously reported in the literature occurred laterally.

As tables 1 and 2 demonstrate, the occurrence of dermoid cysts has a bimodal age distribution, with most cases either occurring during the first year of life or during the teenage years. The significant number of cases treated during adolescence may reflect an increase in the size of a small asymptomatic dermoid cyst as a result of increased hormonal activity during puberty (e.g. increased sebaceous gland activity) ${ }^{5}$.

Magnetic resonance imaging can precisely delineate the outline of a tongue lesion from the surrounding structures and identify its relationship to surrounding structures such as muscle. Characteristic MRI findings of a dermoid cyst of the tongue include ${ }^{6}$ a well 
circumscribed unilocular mass that often demonstrates scattered hyperintense foci in a hypointense background (relative to muscle) on T1-weighted images . On T2-weighted images, dermoid cysts typically appear hyperintense or heterogenous.

Complications resulting from dermoid cysts are unusual. Infection of the cyst can occur, resulting in fistulous tract formation. Disruption of the cyst wall occurs infrequently, leading to a foreign body giant cell reaction against exposed keratin. Rare cases of carcinomatous transformation in the cyst lining have been described ${ }^{7}$.

Treatment of the lingual dermoid cyst consists of conservative surgical excision. In the case of extremely large lesions, marsupialization has been employed.

In summary, although rare, the dermoid cyst should be considered in the differential diagnosis of a tongue swelling in the newborn and adolescent age groups. 
Table 1: Previously Reported Lingual Dermoid Cysts in the English Language Literature

\begin{tabular}{|c|c|c|c|c|}
\hline Author & Age & Sex & Location & $\begin{array}{l}\text { Maximum } \\
\text { Diameter }(\mathrm{cm})\end{array}$ \\
\hline Goldberg $\mathrm{AF}^{8} 1965$ & 22 years & $\mathrm{M}$ & left ventral & 0.4 \\
\hline Smolansky SJ et al ${ }^{9} 1979$ & $\begin{array}{l}10 \\
\text { weeks }\end{array}$ & $\mathrm{F}$ & right lateral & 2.0 \\
\hline Mathur SK et al ${ }^{10} 1980$ & 13 years & $\mathrm{F}$ & anterior & 10.0 \\
\hline Guinta JL et al ${ }^{11} 1982$ & 5 years & $\mathrm{M}$ & dorsal midline & 0.7 \\
\hline Flom GS et al $^{12} 1989^{*}$ & 8 years & $\mathrm{F}$ & dorsal midline & 3.0 \\
\hline 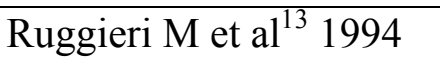 & 12 years & $\mathrm{F}$ & left lateral & 3.0 \\
\hline Miles LP et al ${ }^{14} 1997$ & 10 years & $\mathrm{F}$ & left lateral & 3.0 \\
\hline Myssiorek D et al ${ }^{15} 2000$ & 17 years & $\mathrm{F}$ & $\begin{array}{l}\text { intralingual/ventr } \\
\text { al }\end{array}$ & 6.0 \\
\hline Myssiorek D et $\mathrm{al}^{15} 2000$ & $\begin{array}{l}5 \\
\text { months }\end{array}$ & $\mathrm{M}$ & intralingual & 2.2 \\
\hline
\end{tabular}

* This case was initially published in June $1989^{16}$, but was reprinted ${ }^{12}$ due to incorrect placement of the graphics. 
Table 2: Lingual Dermoid Cysts: Long Island Jewish Medical Center Cases (01/01/1989 to $02 / 28 / 2002)$

\begin{tabular}{|l|l|l|l|l|l|}
\hline Case & Year & Age & Sex & Location & $\begin{array}{l}\text { Maximum } \\
\text { Diameter } \\
(\mathrm{cm})\end{array}$ \\
\hline 1 & 1991 & 10 years & $\mathrm{F}$ & $\begin{array}{l}\text { right ventral } \\
\text { tongue/sublingual }\end{array}$ & Not available \\
\hline $2^{*}$ & 1996 & 17 years & $\mathrm{F}$ & ventral tongue & 6.0 \\
\hline $3^{*}$ & 1996 & 5 months & $\mathrm{M}$ & $\begin{array}{l}\text { intralingual/ventral } \\
\text { tongue }\end{array}$ & 2.2 \\
\hline 4 & 2002 & 14 years & $\mathrm{M}$ & $\begin{array}{l}\text { ventral tongue } \\
\text { velu }\end{array}$ & 4.0 \\
\hline 5 & 2002 & 12 years & $\mathrm{M}$ & $\begin{array}{l}\text { intralingual/ventral } \\
\text { tongue }\end{array}$ & 3.2 \\
\hline
\end{tabular}

* Previously reported by Myssiorek et $\mathrm{al}^{15}$. 
Figure 1: Case 1. (A) Medium power view of lingual dermoid cyst. (B) High power view showing multiple hair follicles within the cyst wall in addition to sebaceous elements (hematoxylin and eosin stain, original magnifications 100x and 400x). 


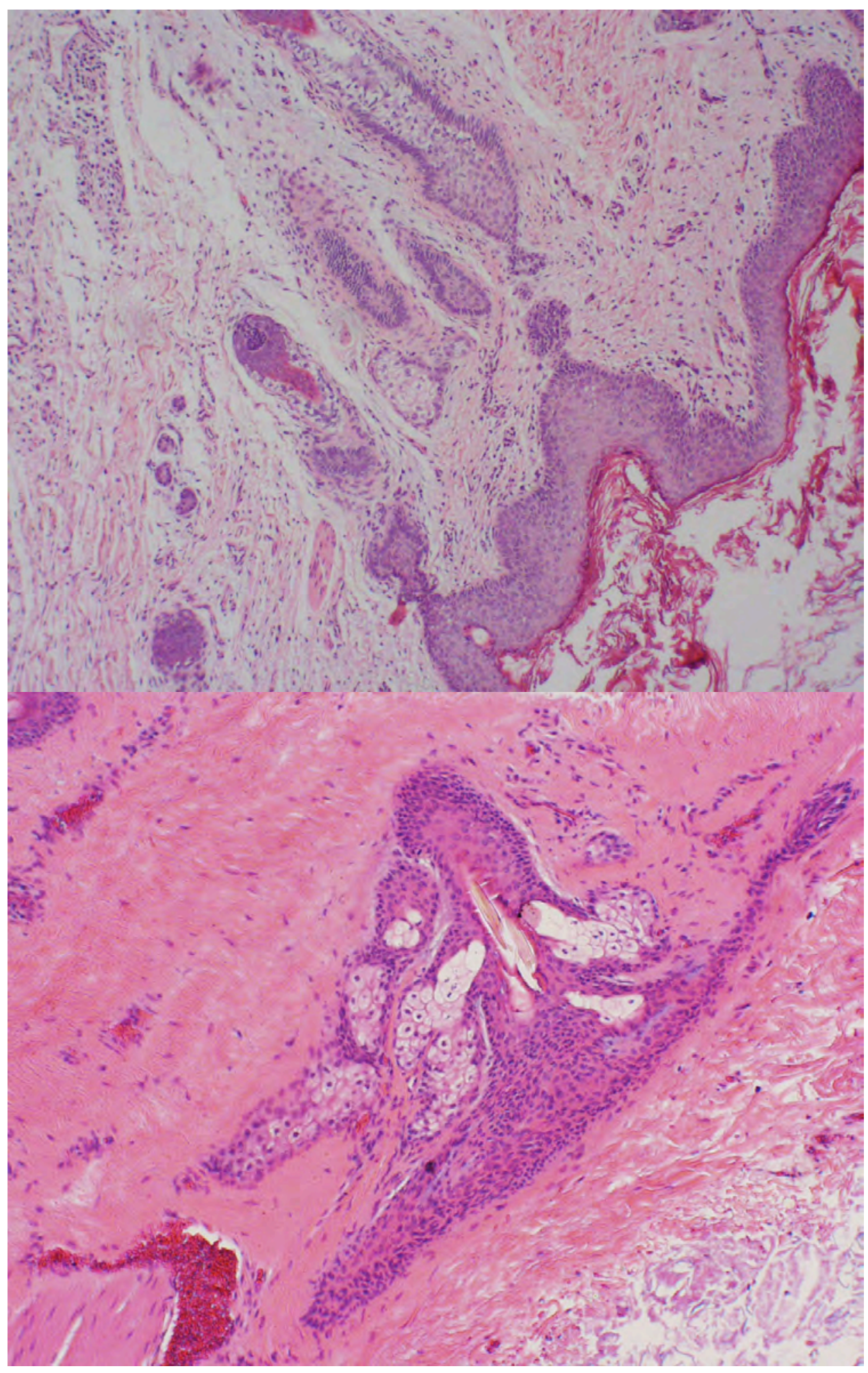


Figure 2: Case 2. Sagittal T2-weighted MRI demonstrates a well-circumscribed mass of the tongue with mixed hypo- and hyperintense areas. The MRI was obtained prior to the fine needle aspiration biopsy.

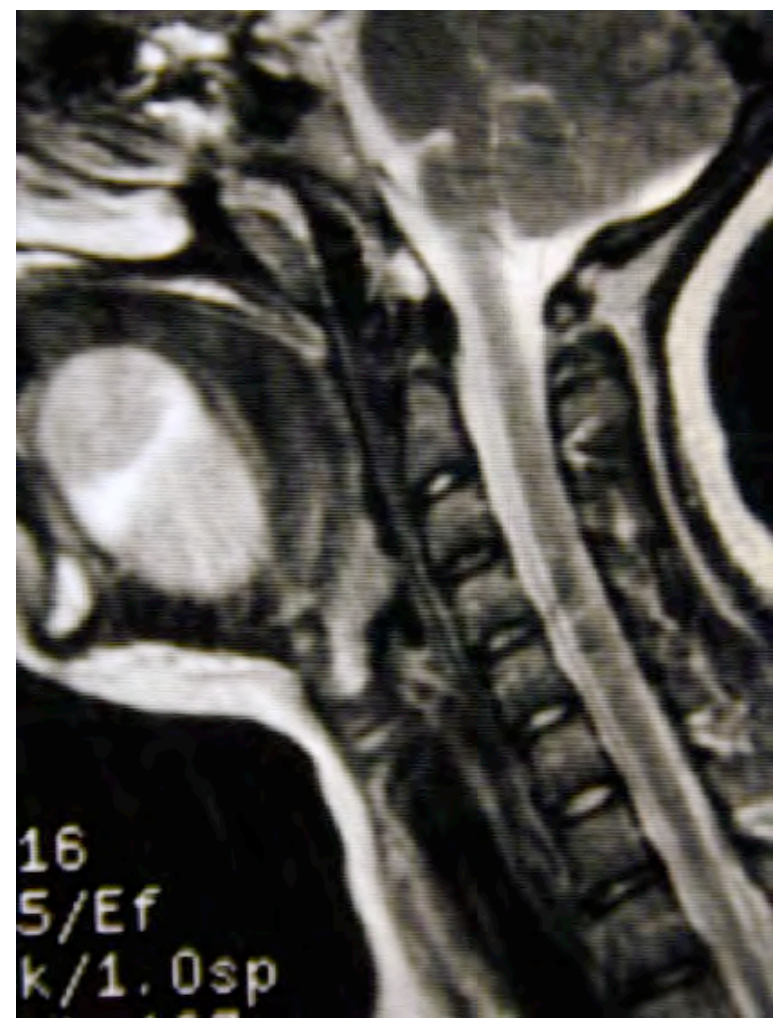


Figure 3: Case 3. Sagittal T2-weighted MRI demonstrates a large hyperintense tongue mass surrounded by a hypointense rim.

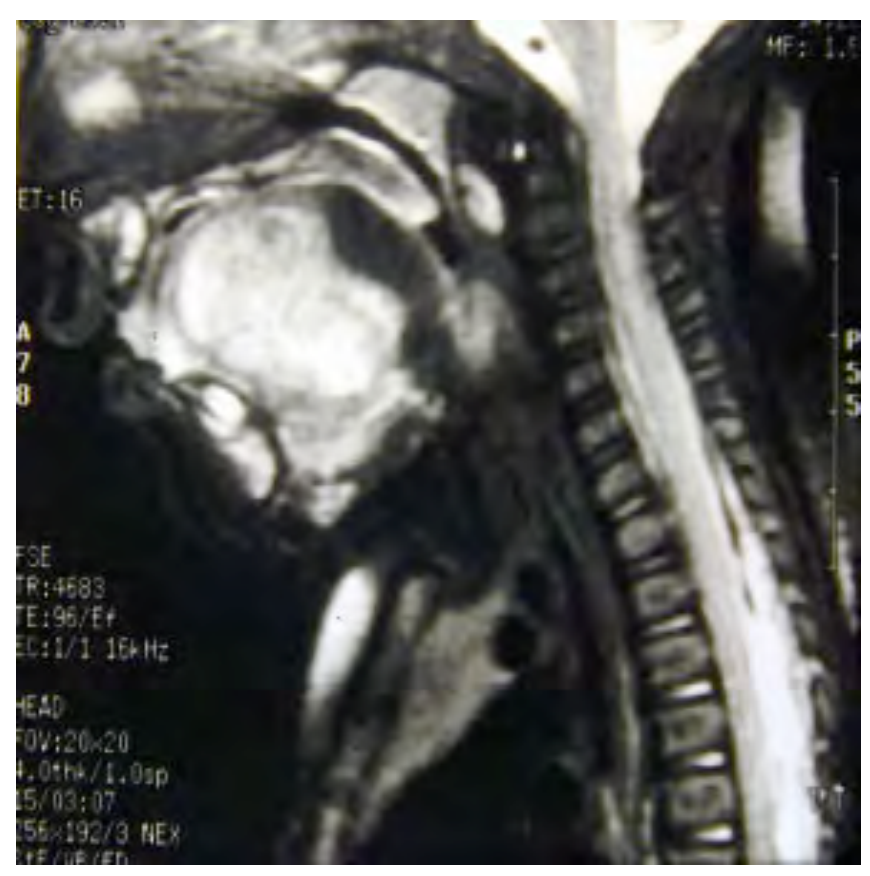


Figure 4: Case 4. Surgical specimen of dermoid cyst of tongue,. (A) Anterior smooth surface. (B) The bisected cyst, revealing a thin wall and a homogeneous smooth tan center.

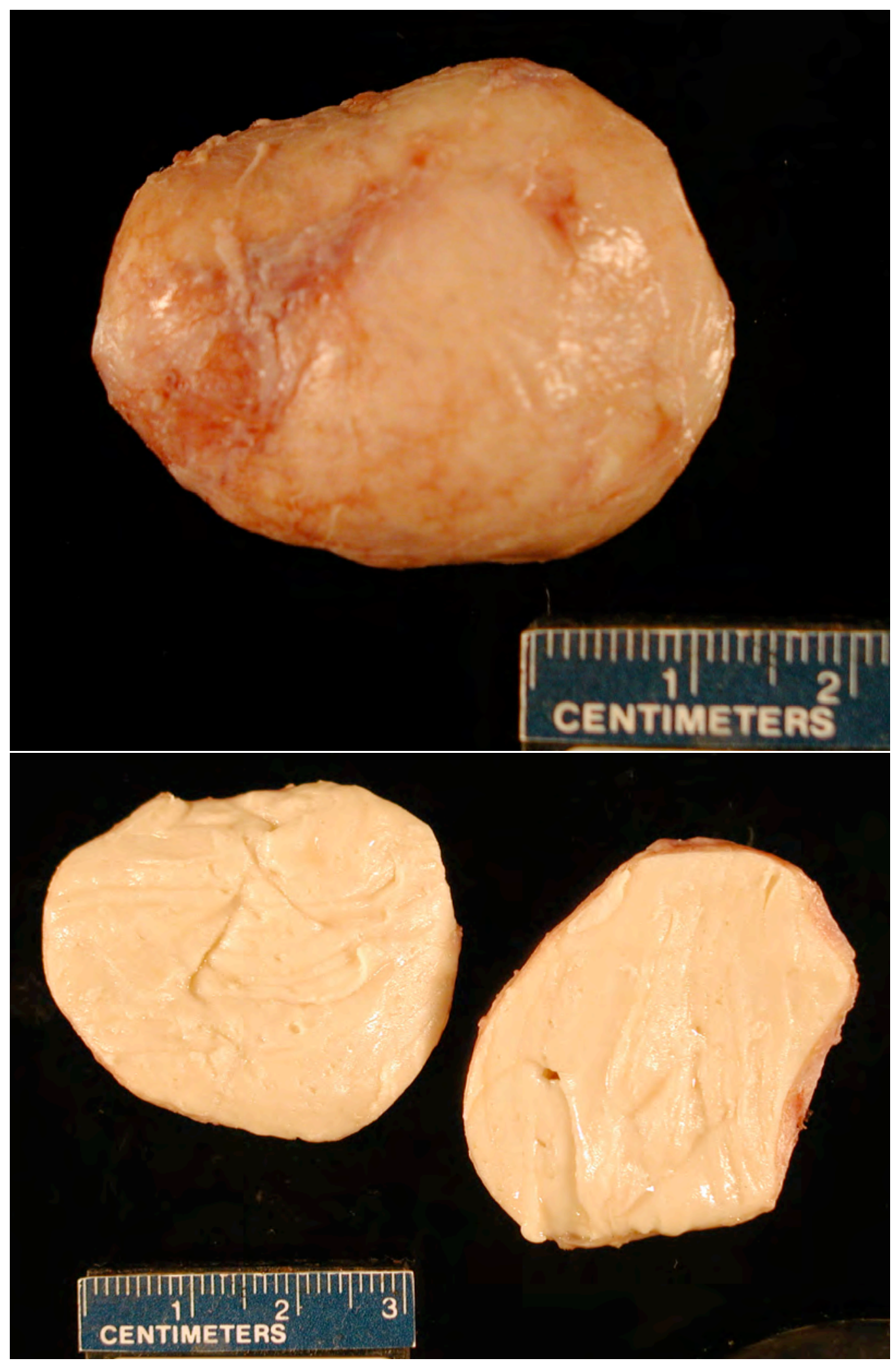


Figure 5: Case 4. Low power view of lingual dermoid cyst demonstrating a stratified squamous epithelial lining, orthokeratin production and a sebaceous gland within the cyst wall (hematoxylin and eosin stain, original magnification 100x).

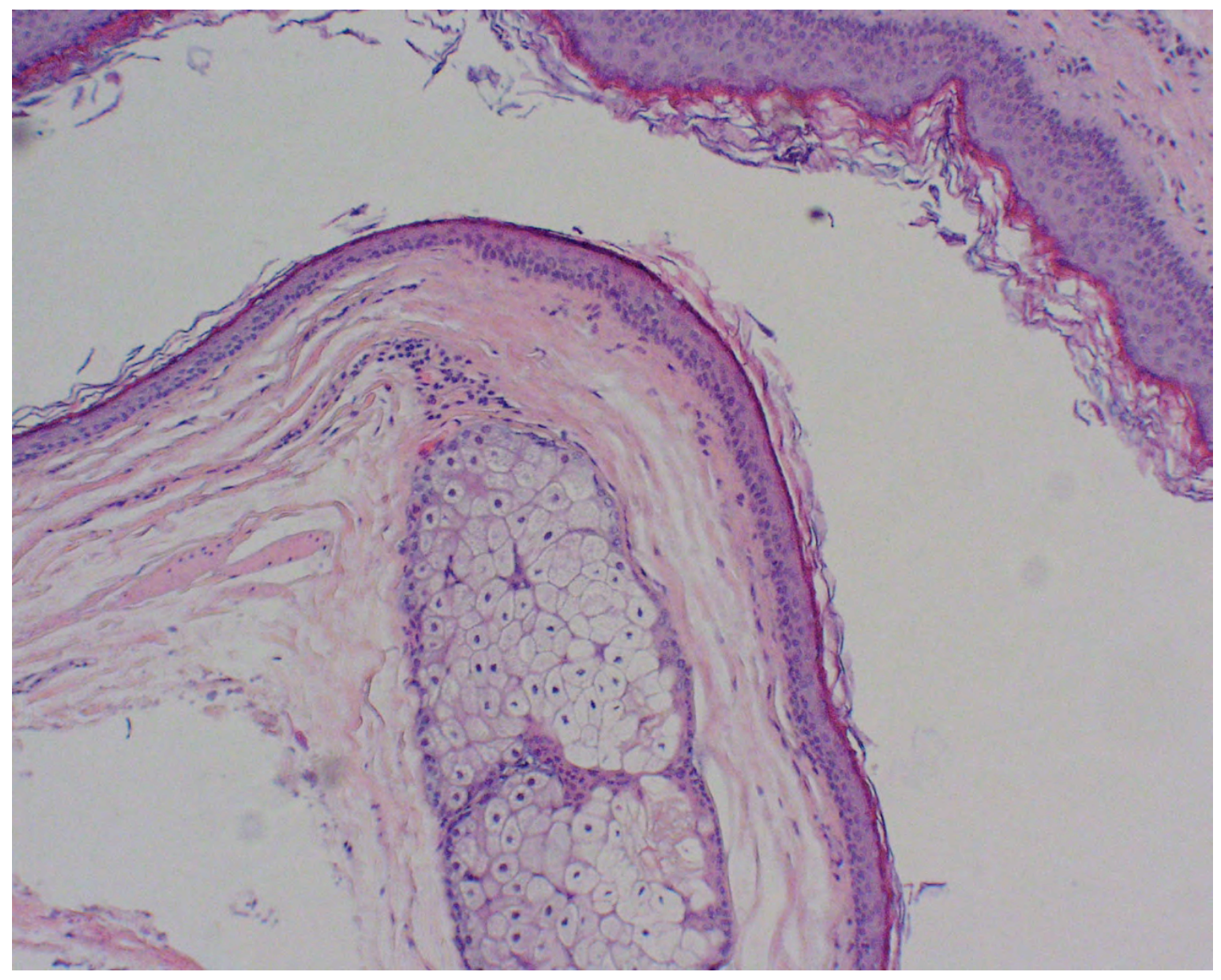




\section{REFERENCES}

${ }^{1}$ Neville BW, Damm DD, Allen CM, Bouquot JE. Developmental defects of the oral and maxillofacial region. In: Oral and Maxillofacial Pathology. Second edition. 2002; 1-44. W.B. Saunders Company, Philadelphia PA.

${ }^{2}$ Liptak JM, Canfield PJ, Hunt GB. Dermoid cyst in the tongue of a dog. Australian Veterinary Journal 2000; 78: 160-161.

${ }^{3}$ Ten Cate AR. Embryology of the head, face, and oral cavity. In: Oral Histology: Development, Structure, and Function. Second edition. 1985; 13-42. C.V. Mosby Company, St. Louis MO.

${ }^{4}$ Myer I. Dermoid cysts of the floor of the mouth. Oral Surg 1955; 8: 1149-1164.

${ }^{5}$ Seward GR. Dermoid cysts of the floor of the mouth. Brit J Oral Surg 1965; 3: 36-47.

${ }^{6}$ Singh P, Mani NB, Mitra S, Suri S. Dermoid cyst of the tongue: magnetic resonance imaging. J Otolaryngol 2002; 31: 179-181.

${ }^{7}$ Devine JC, Jones DC. Carcinomatous transformation of a sublingual dermoid cyst: A case report. Int J Oral Max Surg 2000; 29: 126-127.

${ }^{8}$ Goldberg AF. Dermoid cyst of the tongue: report of case. J Oral Surg 1965; 23: 649.

${ }^{9}$ Smolansky SJ, Cardinal JP, Saffos RO. ENT J 1979; 58: 11-14.

${ }^{10}$ Mathur SK, Menon PR. Dermoid cyst of the tongue: Report of a case. Oral Surg Oral Med Oral Path 1980; 50: 217-8.

${ }^{11}$ Guinta JL, Friedman AL, Karp R. Dermoid cyst of the tongue with sinus tract. Oral Surg 1982; 53: 450-453.

${ }^{12}$ Flom GS, Donovan TJ, Landgraf JR. Congenital dermoid cyst of the anterior tongue. Otolarnygology Head and Neck Surg 1989; 101: 388-391. 
${ }^{13}$ Ruggieri M, Tine A, Rizzo R, Micali G, Fiumara A. Lateral dermoid cyst of the tongue: case report. Int J Ped Otorhinolaryngology 1994; 30: 79-84.

${ }^{14}$ Miles LP, Naidoo LC, Reddy J. Congenital dermoid cyst of the tongue. J Laryngol Otol 1997; 111: 1179-1182.

${ }^{15}$ Myssiorek D, Lee J, Wasserman P, Lustrin E. Intralingual dermoid cysts: A report of two new cases. ENT 2000; 9: 380-383.

${ }^{16}$ Flom GS, Donovan TJ, Landgraf JR. Congenital dermoid cyst of the anterior tongue. Otolarnygology Head and Neck Surg 1989; 100: 602-605. 